\title{
SIMULASI ANSYS 14.0 KEKUATAN IMPAK JATUH BEBAS PADA STRUKTUR ATAP MOBIL DARI BAHAN KOMPOSIT POLYMERIC FOAM DIPERKUAT SERAT TANDAN KOSONG KELAPA SAWIT
}

\author{
Abdullah Y. Harahap1, Syahrul Abda ${ }^{2}$, Bustami Syam ${ }^{3}$, Marragi M. ${ }^{4}$, Tugiman ${ }^{5}$ \\ 1,2,3,4,5 Departemen Teknik Mesin, Fakultas Teknik, Universitas Sumatera Utara \\ Email: ya_qub@ymail.com
}

\begin{abstract}
ABSTRAK
Tandan kosong kelapa sawit jumlahnya sangatlah melimpah dikarenakan pabrik pengolahan kelapa sawit yang terdapat di Indonesia memiliki jumlah yang sangat banyak, menurut survey yang dilakukan limbah tandan kosong kelapa sawit saat ini mencapai 20 juta ton. Tandan kosong kelapa sawit memiliki nilai ekonomis untuk direkayasa sebagai bahan alternatif yang dapat dimanfaatkan dengan alasan masih berlimpahnya bahan baku, bebas korosi, tahan dan mampu menyerap panas, oleh karena itu serat tandan kosong kelapa sawit dapat dimanfaatkan sebagai penguat bahan komposit polymeric foam. Tujuan penelitian ini untuk mengetahui proses pembuatan, menganalisa kekuatan struktur atap mobil terhadap beban impak jatuh bebas dengan mensimulasikan dengan meggunakan perangkat lunak Ansys 14.0. Pembuatan struktur atap mobil dari bahan komposit polymeric foam dibuat menggunakan metode penuagan langsung yang terdiri dari bahan matrik dan penguat. Matrik resin BTQN 157 EX, poliuretan dibuat dari campuran poliol dengan isosianat, serta katalis MEKPO dan sebagai penguat adalah serat tandan kosong kelapa sawit. Dari proses simulasi yang dilakukan dengan perangkat lunak Ansys 14,0, maka diperoleh hasil simulasi perangkat lunak Ansys 14.0 diperoleh $\left(\sigma_{\text {maks }}\right)=31130[\mathrm{~Pa}]$.
\end{abstract}

Kata kunci: Serat tandan kosong kelapa sawit, komposit, polymeric foam, uji impak jatuh bebas, simulasi Ansys 14.0

\section{PENDAHULUAN}

Atap mobil dalam perencanaannya harus terdapat berbagai kelebihan-kelebihan yang dapat diperoleh dari hasil design virtual, maka dari itu perencanaan keunggulan dari yang akan diproduksi memiliki tiga kelebihan utama antara lain faktor keamanan yang terjamin, berat yang semakin ringan, serta biaya produksi yang lebih murah. Saat ini perkembangan teknologi akan material (bahan) semakin pesat. Oleh karena itu penulis mencoba untuk melakukan penelitian mengenai penggunaan komposit serat TKKS diharapkan dapat menjadi acuan dan alternatif baru dalam pembuatan suatu produk yang dapat diperbaharui dan didaur ulang sementara hasil penelitian yang telah dilakukan oleh sebuah institusi komersial terhadap komposisi material kimianya diketahui bahwa kandungan material serat dalam TKKS merupakan kandungan maksimum sekaligus dengan membua simulasi Ansys 14.0, untuk mengetahui kekuatan material tersebut.

\section{TINJAUAN PUSTAKA}

\section{Komposit}

Pada umumnya bentuk dasar suatu bahan komposit adalah tunggal dimana merupakan susunan dari paling tidak terdapat dua unsur yang bekerja bersama untuk menghasilkan sifat-sifat bahan yang berbeda terhadap sifat-sifat unsur bahan penyusun. Komposit terdiri suatu bahan utama (Matrik-matrik) dan suatu jenis penguatan (reinforcement) yang ditambahkan untuk meningkatkan kekuatan dan kekakuan matrik. Penguatan ini biasanya dalam bentuk serat (fibre). Material komposit terdiri dari lebih dari satu tipe material dan dirancang untuk mendapatkan kombinasi karakteristik terbaikn dari setiap komponen penyusunnya. Bahan komposit memiliki banyak keunggulan, 
diantaranya berat yang lebih ringan, kekuatan dan ketahanan yang lebih tinggi, bahan korosi dan ketahahn aus [1].

\section{Matrik \\ Resin Poliester Tak Jenuh}

Pada umumnya polyester tahan terhadap asam kecuali asam pengoksida, tetapi lemah terhadap alkali. Bila dimasukkan kedalam air mendidih dalam waktu yang lama (300 jam), bahan akan pecah dan retak-retak. Bahan ini mudah mengambang dalam pelarut, yang melarut polimer stiren. Kemampuan terhadap cuaca sangat baik. Tahan terhadap kelembaban dan sinar UV bila dibiarkan diluar, tetapi sifat tembus cahaya rusak dalam beberapa tahun. Bahan ini dapat digunakan secara luas sebagai bahan komposit. Polyester yang 157 BQTN-EX dengan spesifikasi seperti ditampilkan dalam tabel 2.1 di bawah ini.

Tabel 2.1 Karakteristik Mekanik Polister Resin Tak Jenuh

\begin{tabular}{lll}
\hline Sifat Mekanik & Satuan & Besaran \\
\hline Berat Jenis & $\mathrm{kg} / \mathrm{mm}^{3}$ & $1,215 \times 10^{-6}$ \\
Modulus & $\mathrm{MPa}$ & 2.941 \\
Elastisitas & $\mathrm{MPa}$ & 54 \\
Kekuatan Tarik & $\%$ & 1,6 \\
Elongas & $\mathrm{Mpa}$ & 5,5 \\
\hline
\end{tabular}

Polyester adalah resin thermoset yang berbentuk cair dengan viskositas yang relatif rendah, dengan penambahan katalis, Polyester mengeras pada suhu kamar [2].

\section{Blowing Agent}

Material yang terbentuk dari campuran blowing agent polimer disebut dengan material polymeric foam. Material polymeric foam banyak ditemukan sebagai busa kaku dan fleksibel yang digunakan sebagai pelapis atau perekat material. Berdasarkan sifat mekaniknya material ini memiliki 4 (empat) sifat penting diantaranya:

1. Sifat Elastik

Sifat ini berhubungan dengan sifat kekakuan material yang terdiri dari geometri, bentuk dan mikrostrukturnya.

2. Sifat Viskoelastik

Sifat peredaman solid material, sifat ini merupakan efek dari bentuk geometri material tersebut.

3. Sifat Akustik

Sifat ini berhubungan dengan sifat media yang dilewati oleh perambatan suara akibat bentuk struktur yang berongga akan memudahkan gelombang udara masuk ke dalam material dan terserap atau terperangkap sebagian besar ke dalam struktur tersebut. Dengan demikian suara yang keluar dan atau dipantulkan oleh material polymeric foam akan mengalami pelemahan.

4. Sifat Viskoakustik

Sifat ini berhubungan dengan peredaman fluida yang dihubungkan dengan geometri, bentuk mikrostrukturnya yang sama dengan sifat elastiknya [3].

\section{Katalis Mekpo}

Katalis merupakan material kimia yang digunakan untuk mempercepat proses reaksi polimerisasi struktur komposit pada kondisi suhu kamar dan tekanan atmosfir. Pemberian katalis dapat berfungsi untuk mengatur waktu pembentukan gelembung blowing agent, sehingga tidak mengembang secara berlebihan, atau terlalu capat mengeras yang dapat mengakibatkan terhambatnya pembentukan gelembung [4].

\section{Penguat}

Dalam penelitian ini sebagai penguat yang digunakan adalah serat tandan kosong kelapa sawit (TKKS). Kebanyakan serat TKKS setelah siap dipakai khususnya diperkebunan sering dibuang sebagai limbah dan hanya sedikit yang dapat digunakan untuk diproduksi atau didaur ulang. Dan 
peneliti ingin coba mengamati sifat atau karakteristik dari serat ini karena sifatnya yang kuat dan juga ringan jika dicampur dengan bahan-bahan yang lain. Di indonesia merupakan negara dengan perkebunan kelapa sawit terluas di dunia berjuta ha (Deptan). Tiap harinya berton-ton kelapa sawit yang diolah. TKKS adalah salah satu produk samping kelapa sawit. Setiap ton kelapa sawit yang diolah diperoleh TKKS yang mencapai 250 [kg] [5].

\section{Ansys 14.0Workbench}

Ansys 14.0 Workbenchadalah suatu perangkat lunak komputer umum yang mampu menyelesaikan persoalan-persoalan elemen hingga dari permodelan hingga analisis. Ansys 14.0Workbench ini digunakan untuk mensimulasikan semua disiplin ilmu fisika baik statis maupun dinamis, analisis struktural (kedua-duanya linier dan nonlinier), perpindahan panas, dinamika fluida, dan elektromagnetik untuk para enginer.

Ansys 14.0Workbench dapat mengimport data CAD dan juga memungkinkan untuk membangun geometri dengan kemampuan yang "preprocessing". Demikian pula dalam preprocessor yang sama, elemen hingga model (jaring alias) yang diperlukan untuk perhitungan dihasilakan. Setelah mendefenisikan beban dan melakukan analisis, hasil dapat dilihat sebagai numerik dan grafis [6].

\section{Standar Atap Mobil}

Kekuatan atap mobil memang sangat jarang sekali diperhatikan oleh produsen mobil. Hal tersebutlah yang membuat Insurance Institute for Highway Safety (IIHS) saat ini juga melakukan tes kekuatan atap selain tes tabrak. Daya tahan atap juga akan diukur menggunakan sensor-sensor dan mobil yang berhasil dinyatakan lulus tes kekuatan atap harus mampu menahan empat kali bobot kendaraan atau perbandingan kekuatannya 1:4. Misalnya saja sebuah mobil memiliki bobot 2 ton, maka atap mobil tersebut harus mampu menyanggah beban seberat 8 ton agar lulus uji kekuatan atap, maka atap dijamin tidak akan rusak [7].

\section{METODOLOGI PENELITIAN}

Adapun langkah-langkah dari pembuatan struktur atap mobil adalah sebagai berikut:

1. Mempersiapkan serat tandan kosong kelapa sawit.

2. Memotong serat tandan kosong kelapa sawit dengan menggunakan mesin pencacah serat.

3. Mempersiapkan timbangan digital.

4. Mempersiapkan tempat penampung bahan seperti: cap, ember dan lain-lain.

5. Mempersiapkan pengaduk bahan komposit komposit polymeric foam diperkuat serat tandan kosong kelapa sawit.

6. Mempersiapkan cetakan struktur komposit Polymeric foam dan oleskan Wax pada permukaan cetakan agar struktur yang akan dicetak mudah dilepaskan dari cetakan.

7. Mempersiapkan bahan pembentuk sturuktur komposit Polymeric foam diperkuat serat TKKS. Adapun bahan yang harus dipersiapkan dalam proses pembuatan struktur komposit Polymeric foam.

8. Timbang bahan resin BTQN $157 \mathrm{EX}$, serat, isosianat, polyol dan katalis sesuai dengan komposisinya.

9. Tuangkan serat tandan kosong kelapa sawit dan resin ke dalam tempat pengadukan (ember) dan aduk hingga merata dengan batang pengaduk yang terbuat dari kayu.

10. Campurkan isosianat dengan polyol (Blowing Agent) kemudian aduk hingga merata dan tuangkan ke dalam tempat pengadukan serat tandan kosong kelapa sawit dengan resin, setelah itu aduk kembali hingga merata.

11. Tuangkan katalis ke dalam tempat pengadukan dan aduk kembali hingga merata dan semua bahan sudah siap untuk dicetak.

12. Tuangkan semua bahan ke dalam cetakan yang sudah disiapkan hingga merata pada semua bagian cetakan kemudian tutup dengan penutup cetakan.

13. Tunggu campuran tersebut bereaksi pada tekanan atmosfir pada suhu kamar, proses pengerasan akan terjadi disertai dengan terbentuknya gelembung udara pada bahan komposit Polymeric foam diperkuat serat TKKS. 
14. Setelah material mengeras tunggu selama \pm 24 jam kemudian lepas cetakan dari material komposit Polymeric foam diperkuat serat TKKS dan material sudah siap di uji impak jatuh bebas.

\section{Proses Simulasi Ansys 14.0}

Setelah diinstal perangkat lunak Ansys 14.0 pada komputer ataupun leptop kemudian buka perangkat lunak dan siap digunakan untuk disimulasikan. Berikut adalah langkah-langkah yang akan dilakukan pada simulasi dibawah ini:

1. Bukalah program ansys 14.0 , dan pilihlah program static structural.

2. Pilihlah enginering data, kemudian isi data enginering yang akan digunakan.

3. Return to project kemudian pilihlah Geometry untuk mendesain Gambar yaitu membuat Gambar yang akan didesain.

4. Pemberian meshing pada benda.

5. Memasukkan parameter simulasi yaitu fixed support, force. Untuk pemberian tekanan pada bagian atas struktur, dengan memasukkan nilai 'force'

6. Langkah berikutnya adalah menentukan variabel yang akan disimulasi, dalam simulasi ini adalah tegangan.

\section{HASIL DAN PEMBAHASAN}

Hasil Simulasi Ansys 14.0

Berdasarkan hasil simulasi ansys 14.0 pada struktur $\mathrm{A}_{1-1}$, pemberian gaya maksimum sebesar 68,67 N, maka diperoleh tengangan maksimum sebesar 31998 Pa dapat dilihat pada Gambar 4.13 di bawah ini.

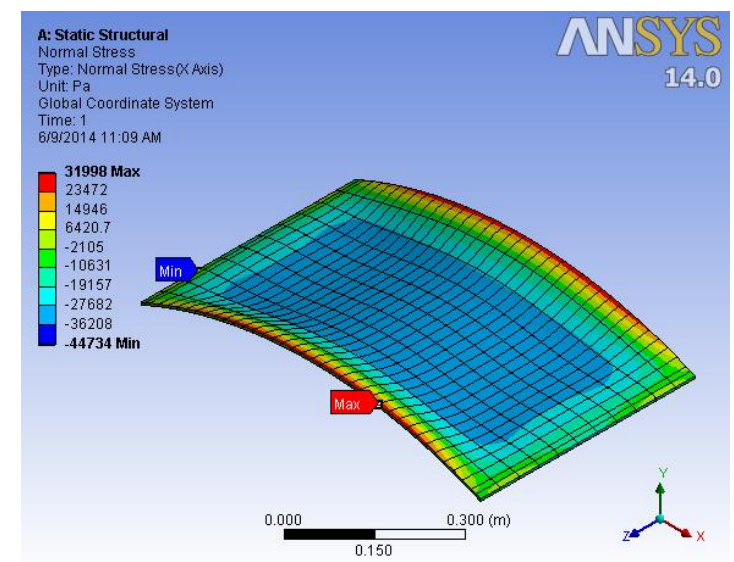

Gambar 4.13 Distribusi tegangan Struktur Atap Mobil Dengan Gaya 68,67 N

Berdasarkan hasil simulasi ansys 14.0 pada struktur $\mathrm{A}_{2-1}$, pemberian gaya maksimum sebesar 66,8061 N, maka diperoleh tengangan maksimum sebesar 31130 Pa dapat dilihat pada Gambar 4.14 di bawah ini.

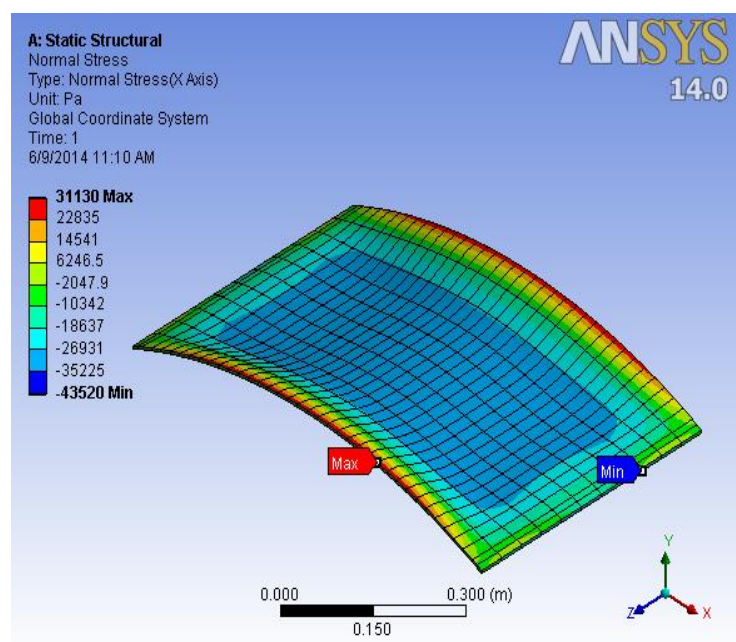

Gambar 4.14 Distribusi tegangan Struktur Atap Mobil Dengan Gaya 66,8061 N 
Berdasarkan hasil simulasi ansys 14.0 pada struktur $\mathrm{A}_{3-1}$, pemberian gaya maksimum sebesar $70,7301 \mathrm{~N}$, maka diperoleh tengangan maksimum sebesar $32958 \mathrm{~Pa}$ dapat dilihat pada Gambar 4.15 di bawah ini.

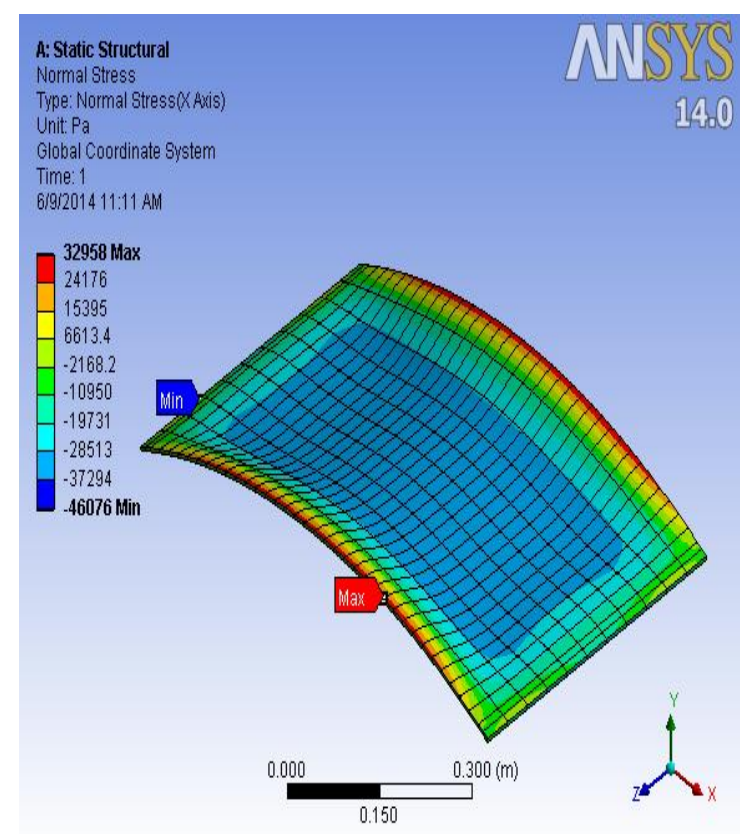

Gambar 4.15 Distribusi tegangan Struktur Atap Mobil Dengan Gaya 70,7301 N

Berdasarkan hasil simulasi ansys 14.0 pada struktur $\mathrm{A}_{1-2}$, pemberian gaya maksimum sebesar $123,7040 \mathrm{~N}$, maka diperoleh tengangan maksimum sebesar 57642 Pa dapat dilihat pada Gambar 4.16 di bawah ini.

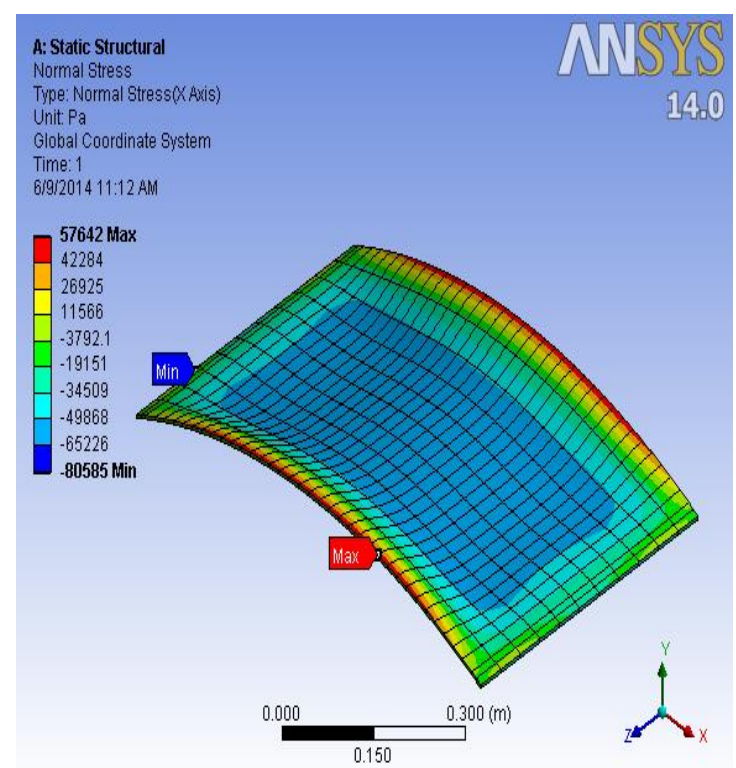

Gambar 4.16 Distribusi tegangan Struktur Atap Mobil Dengan Gaya 123,7040 N

Berdasarkan hasil simulasi ansys 14.0 pada struktur $\mathrm{A}_{2-2}$, pemberian gaya maksimum sebesar 97,2171 N, maka diperoleh tengangan maksimum sebesar $45300 \mathrm{~Pa}$ dapat dilihat pada Gambar 4.17 di bawah ini. 


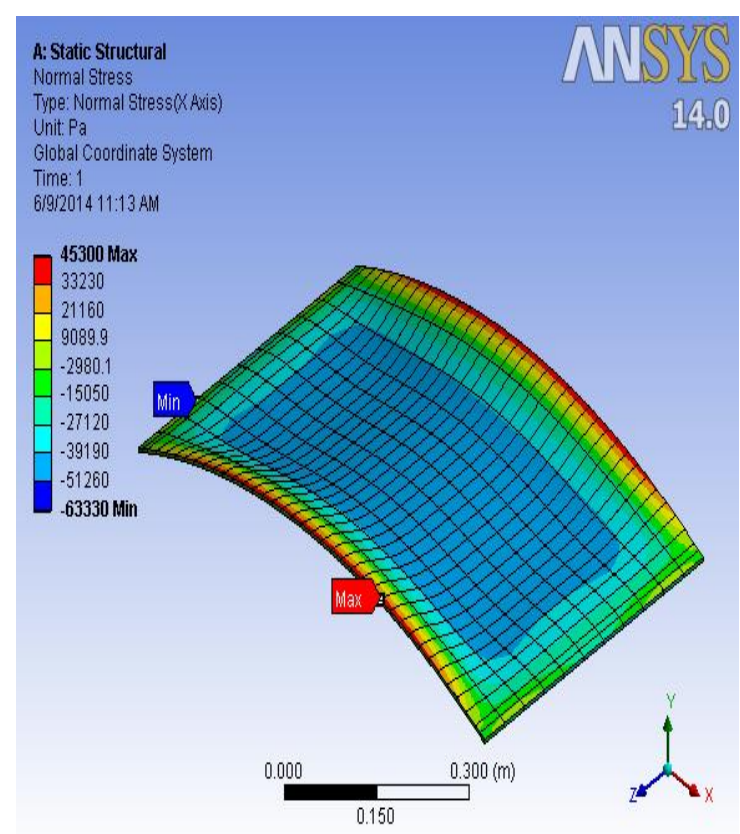

Gambar 4.17 Distribusi tegangan Struktur Atap Mobil Dengan Gaya 97,2171 N

Berdasarkan hasil simulasi ansys 14.0 pada struktur $\mathrm{A}_{3-2}$, pemberian gaya maksimum sebesar $185,6052 \mathrm{~N}$, maka diperoleh tengangan maksimum sebesar $86486 \mathrm{~Pa}$ dapat dilihat pada Gambar 4.18 di bawah ini.

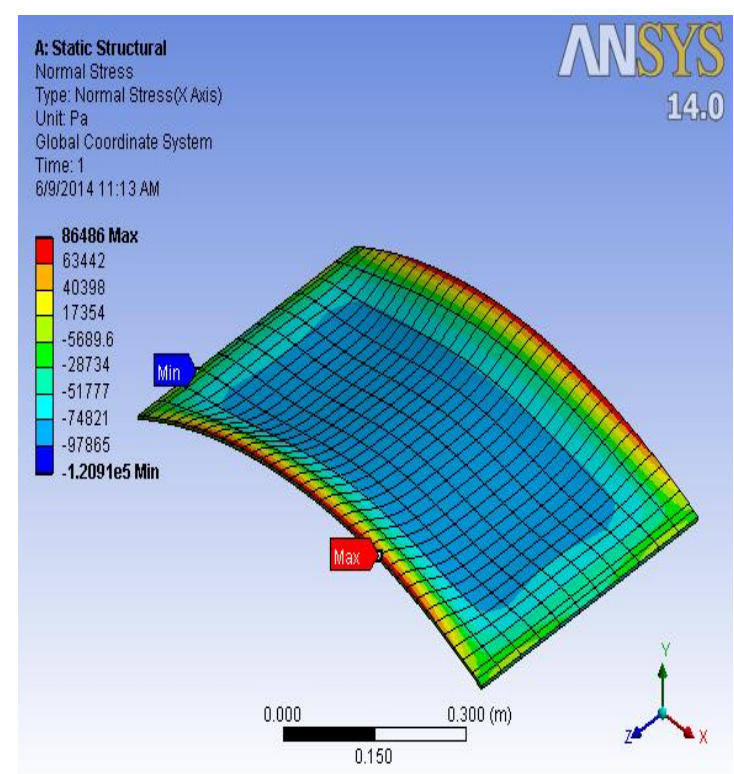

Gambar 4.18 Distribusi tegangan Struktur Atap Mobil Dengan Gaya 185,6052 N

Berdasarkan hasil simulasi ansys 14.0 pada struktur $\mathrm{A}_{1-3}$, pemberian gaya maksimum sebesar $291,6513 \mathrm{~N}$, maka diperoleh tengangan maksimum sebesar $135900 \mathrm{~Pa}$ dapat dilihat pada Gambar 4.19 di bawah ini. 


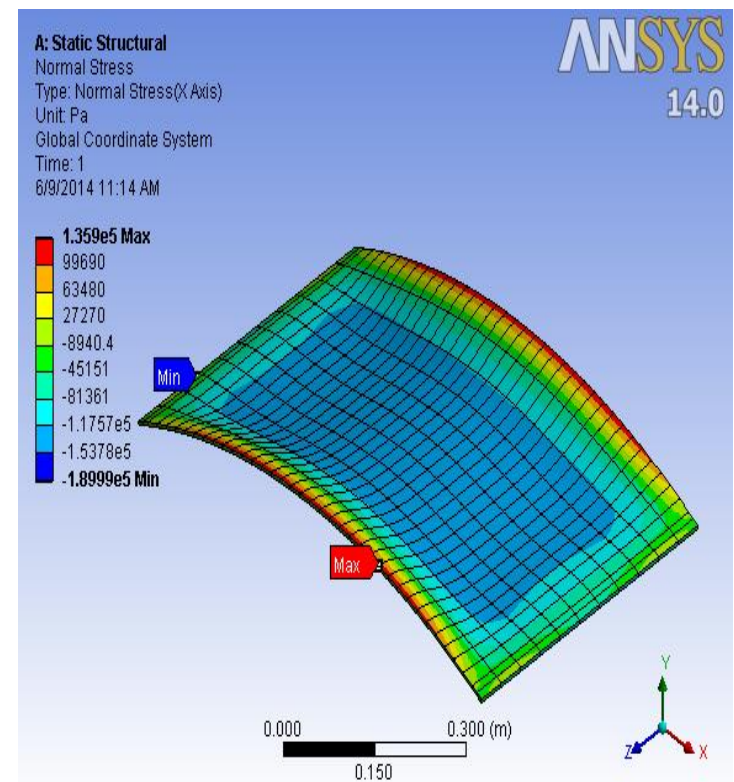

Gambar 4.19 Distribusi tegangan Struktur Atap Mobil Dengan Gaya 291,6513 N

Berdasarkan hasil simulasi ansys 14.0 pada struktur $\mathrm{A}_{2-3}$, pemberian gaya maksimum sebesar 203,2632 N, maka diperoleh tengangan maksimum sebesar $94714 \mathrm{~Pa}$ dapat dilihat pada Gambar 4.20 di bawah ini.

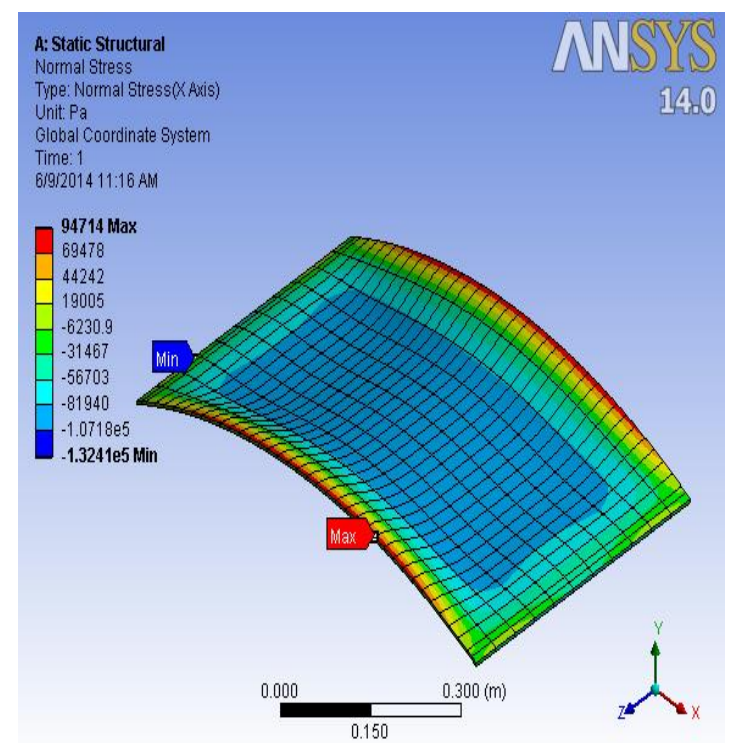

Gambar 4.20 Distribusi tegangan Struktur Atap Mobil Dengan Gaya 203,2632 N

Berdasarkan hasil simulasi ansys 14.0 pada struktur $\mathrm{A}_{3-3}$, pemberian gaya maksimum sebesar 494,9145 N, maka diperoleh tengangan maksimum sebesar 230610 Pa dapat dilihat pada Gambar 4.21 di bawah ini. 


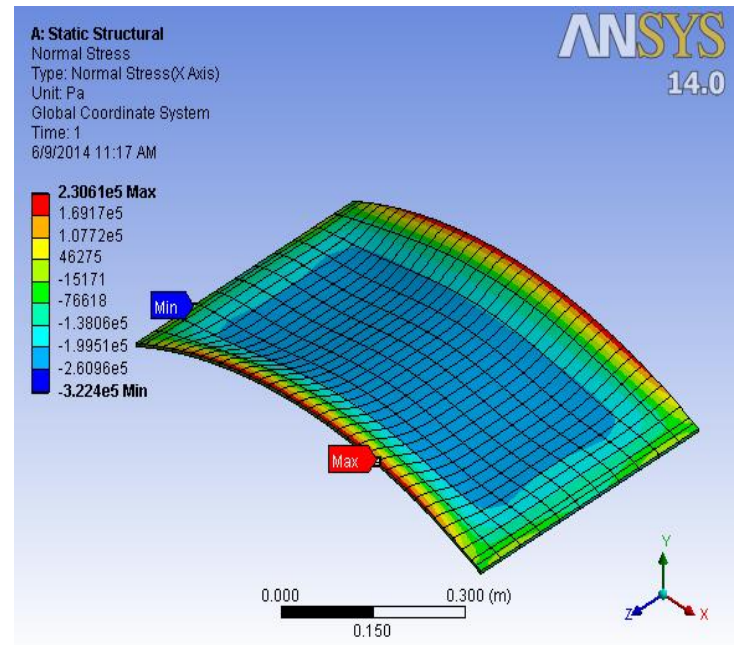

Gambar 4.21 Distribusi tegangan Struktur Atap Mobil Dengan Gaya 494,9145 N

\section{KESIMPULAN}

Beberapa kesimpulan yang diperoleh dari hasil penelitian ini adalah:

1. Proses pembuatan spesimen uji dari bahan polimeric foam yang diperkuat serat TKKS dilakukan dengan teknik penuangan langsung (hand layup), disertai pengadukan lambat dengan cetakan diletakan pada posisi horizontal.

2. Setelah dilakukan pengujian impak jatuh bebas untuk masing-masing struktur uji maka dapat diperoleh kesimpulan bahwa kekuatan struktur atap mobil diperoleh pada struktur $\mathrm{A}_{2-1}$ ketingian $0,5[\mathrm{~m}]$ yaitu: gaya maksimum $\left(F_{\text {Max }}\right)=66,8061[\mathrm{~N}]$, tegangan maksimum $\left(\sigma_{\text {maks }}\right)=29691,6$ $[\mathrm{Pa}]$, momentum $(\mathrm{M})=21,3289[\mathrm{kgm} / \mathrm{s}]$, impuls $(\mathrm{I})=2,0709$ [N.s], Energi impak eksperimen $\left(E_{\text {Ie }}\right)=33,4030[\mathrm{~J}]$, Energi potensial $\left(E_{\mathrm{p}}\right)=31,392[\mathrm{~J}]$ dan Energi serap $\left(\mathrm{E}_{\mathrm{s}}\right)=2,011[\mathrm{~J}]$.

3. Hasil simulasi Ansys 14.0 diperoleh Gaya maksimum yang diberikan diperoleh dari hasil pengujian impak jatuh bebas sebesar 66,8061 [N] maka dapat diperoleh tegangan maksimum $\left(\sigma_{\text {maks }}\right)=31130[\mathrm{~Pa}]$.

\section{DAFTAR PUSTAKA}

[1] Hashim, J. (2013). Pemprosesan Bahan. (Edisi pertama). Johor Baru: Cetak Ratu Sdn. Bhd.

[2] Zulfadli. (2013). Pengembangan Model dan Analisa Reapon Parking Bumper Dari Bahan Polimeric Foam Diperkuat Serat Tandan Kosong Kelapa Sawit.Tugas Skripsi Universitas Sumatera Utara.

[3] Nazaruddin, H.H. (2003). Poliuretan,Polimer Serba Bisa. hhtp://www.chem-is-try.org/artikel_kimia/kimia_material/poliuretan_polimer serba_bisa/. (diakses 13 Februari 2014).

[4] Murdijanto, D.N, setiabudi, A. (2010). Sintesis Karakteristik Dan Uji Aktifitas Katalis $\mathrm{Ni}_{\mathrm{A}} \mathrm{Al}_{2} \mathrm{O}_{3}$ Pada Reaksi Hydrocracking Minyak Nabati. Jurnal Sains Dan Teknologi Kimia. http://file.upi.edu/direktori/jurnal/jurnal_sains_dan_teknologi_kimia/jurnal_sains_dan_teknolog i_kimia_jilid_1_no._1/sintesis,_karakterisasi_dan_uji_aktivitas_katalis_ni_al2o3_pada_reaksi_ hydrocracking_minyak_nabati.pdf. (diakses 4 april 2014).

[5] Amrie, E. (2008). Serat Tandan Kosong Kelapa Sawit. http://www.w3.org/TR/REC-html40, 2008. (diakses 4 januari 2014).

[6] Pinem, M.D. (2013). ANSYS Analisis Sistem Mekanik. Bandung. Wahana Ilmu Kita.

[7] Rudy.K. (2013). IIHS Lakukan Tes Atap. http://www.histats.com"target="_blank"><imgsrc="http://sstatic1.histats.com/0.gif?2045951\& $101 "$ alt="" border="0" $>\langle/ a\rangle$ (diakses 14 Juli 2014). 